\title{
Apple-picking in San Diego
}

\author{
Peter E Lipsky
}

The annual meeting of the American College of Rheumatology in San Diego has just finished. It has been an intense and diverse four-day meeting, much like a giant bazaar, with over 12,000 attendees in all. The convention venue was enormous, the industrial exhibits were extensive, and the presentations had a theatrical quality because of the bright lights needed for recording the sessions: the sensory overload was exhausting. I am reminded of the words of Robert Frost from After Apple Picking,

"For I have had too much

Of apple-picking: I am overtired

Of the great harvest I myself desired".

Indeed, there was a great harvest of new information, reiteration of old information and marketing spin that required a depth of contemplation not possible during the meeting. It will take time to organize and integrate these data. What was the big news at the convention? Presentations encompassed genetic influences and rheumatic disease, the development of new biomarkers, and trial data of new biologics; of these, the results of the Glucosamine/Chondroitin Arthritis Intervention Trial (GAIT) stood out because the data have important implications for patients with osteoarthritis who consider taking glucosamine and chondroitin sulfate. This was a well-controlled study of more than 1,500 patients with knee pain and osteoarthritis.

A number of important results emerged: first, more than $60 \%$ of patients improved with placebo alone; second, treatment with a cyclo-oxygenase 2 inhibitor significantly increased the frequency of response; and third, neither glucosamine nor chondroitin sulfate, either alone or in combination, was different to placebo in the frequency of response. The ...the major

role of large

conventions

is to notify the

clinician that

new data are

available...full

understanding

of the

information

requires

additional

study.

\section{PE Lipsky is}

the Editor-in-

Chief of Nature

Clinical Practice

Rheumatology.

Competing interests

The author declared he has no competing interests.

www.nature.com/clinicalpractice doi:10.1038/ncprheum0086 largely negative results of this important trial were presented in a short talk in a vast room with very little response. The press releases tended to report the trial in a far more positive manner than the data warranted.

The impact of this information is difficult to gauge. Obviously, this study has important implications, but I was uncertain whether the practitioner would have the ability to make an informed decision about how to incorporate these results into clinical decision making. Indeed, I wondered whether this was the best format to convey important information with immediate clinical impact. I think not. I believe that it is difficult for most people (myself included) to fully understand the implications of new data in such a setting, and that other methods are far more effective for conveying information in a meaningful way. One of them could be the approach taken by Nature Clinical Practice Rheumatology (NCPR). Once the results of GAIT are published, they will be featured in a Practice Point article in NCPR to help the practitioner decide the value of this popular therapy. Although this knowledge might not affect the use of these compounds as 'nutraceuticals', available to individuals without prescription, at least it should provide the practitioner with the ability to discuss this option with patients in an informed manner.

I am coming to the conclusion that the major role of large conventions is to notify the clinician that new data are available to be considered, but that full understanding of the information requires additional study. As a source of high quality, objective information, NCPR will be a valuable aid to practitioners as they form opinions about new data that can have an impact on their daily practice. 